\title{
THE ACTION OF IODOACETATE ON THE ELECTRICAL AND MECHANICAL ACTIVITIES OF THE ISOLATED PER- FUSED FROG HEART ${ }^{1}$
}

\author{
By MORRIS KLEINFELD, EDWARD STEIN, JOHN MAGIN, AND \\ CHARLES E. KOSSMANN
}

\begin{abstract}
(From the Department of Medicine, New York University College of Mcdicine, and the Electrocardiographic Laboratory, Third (N.Y.U.) Medical Division, Bellev'uc Hospital, New' York, N. Y.)
\end{abstract}

(Submitted for publication June 6, 1955; accepted August 3, 1955)

The use of enzyme inhibitors on cardiac tissue has permitted a better understanding of the relationship between derangements of metabolism and function. The metabolic and physiologic actions of iodoacetate (IAA) have been reported by a number of investigators (1-4). In low concentrations IAA has been shown to act as a specific inhibitor of triosephosphate dehydrogenase thereby blocking the glycolytic process $(5,6)$. This is in contrast to its reported action as a general sulfhydryl inhibitor when relatively higher concentrations are employed $(6,7)$. Studies with $\mathrm{C}^{1+}$ labeled pyruvate $(8)$ have shown that the addition of $10^{-3}$ and $10^{-4} \mathrm{M}$ IAA reduces the pyruvate utilization (66 per cent) in heart slices without affecting oxygen consumption whereas greater amounts depress both oxygen consumption and pyruvate disappearance.

Earlier studies on the physiological effects of IAA have demonstrated a depression of contractility and spontaneous rate of isolated rabbit and frog auricles $(2,3)$. In a recent study on the isolated rabbit auricle Gardner, Wilson, and Farah (4) reported that IAA produced far greater effects on contractility and spontaneous rate than on the excitability or the action potential. They predicated the differences in mechanical and electrical behavior on a difference in the energy requirements of these functions. They believe the IAAsensitive functions (such as rhythmicity and contractility) require a greater amount of energy than the IAA-insensitive functions (electrical excitability and action potential) and therefore are affected earlier. In further support of this ex-

1 This work was aided by grants from the American Heart Association and the Western New York State Heart Association. planation these investigators extended their studies to other enzymes inhibitors such as cyanide, dinitrophenol and fluoroacetate, which showed actions on different stages of the energy-producing processes and differential effects on the various cardiac functions similar to those observed with iodoacetate (9).

The present investigation was designed: 1) To extend the study of the effects of IAA to the electrical activity of single ventricular fibers of the frog's heart;2) to correlate the electrical with the mechanical events, using cardiac output as an index of the latter; and 3 ) to observe the modifying effects, if any, of metabolic intermediates such as pyruvate and acetate, and adenosine tri-phosphate (ATP) on the mechanical and electrical activities of the IAA-treated heart.

\section{METHODS}

Frogs (Rana pipicns) in winter stage were used. The animals were pithed and the perfusion technique as described by Bülbring (10) was employed. Frog Ringer's solution was the perfusion medium and contained the following in mEq. per L.: $\mathrm{NaCl} 110 ; \mathrm{KCl} 4.02 ; \mathrm{CaCl}_{2}$ 1.53; $\mathrm{NaHCO}_{3} 4.29$; and glucose 4.11. The venous pressure was varied between 2 and $2.5 \mathrm{~cm}$. $\mathrm{H}_{2} \mathrm{O}$ and the aortic resistance was fixed at a level of $3 \mathrm{~cm}$. above the heart. Iodoacetate $\left(5 \times 10^{-5} \mathrm{M}\right)$ was administered as a constant perfusion. The intracellular action potential was recorded simultaneously with an indirect electrocardiogram (Lead I) on a Sanborn Twin Beam Model 62 electrocardiograph. For the technical details of recording the intracellular potentials reference may be made to a previous publication (11). Cardiac outputs were obtained prior to and at frequent intervals after the administration of the antimetabolite.

In the experiments employing the substrates pyruvate $(0.0055 \mathrm{M})$ and acetate $(0.0055 \mathrm{M})$, and ATP $(1.0 \times$ $\left.10^{-4} \mathrm{M}\right)$, these agents were added to the IAA-Ringer's solution and given as a continuous perfusion. 


\section{RESLLTS}

Iodoacetate $\left(5 \times 10^{-5} \mathrm{MI}\right)$ modified both the electrical and mechanical activity of the isolated perfused frog's heart. The effects on both activities were of similar degree and occurred usually at the same time (Figure 1). The most consistent early change in the electrical record was a shortening of the action potential duration ( $A P d)$ which was progressive. Coincident with this, a shortened $\mathrm{S}-\mathrm{T}$ interval and an abnormal $\mathrm{T}$ wave were observed in the indirect electrocardiogram. Of lesser frequency, and occurring relatively late.

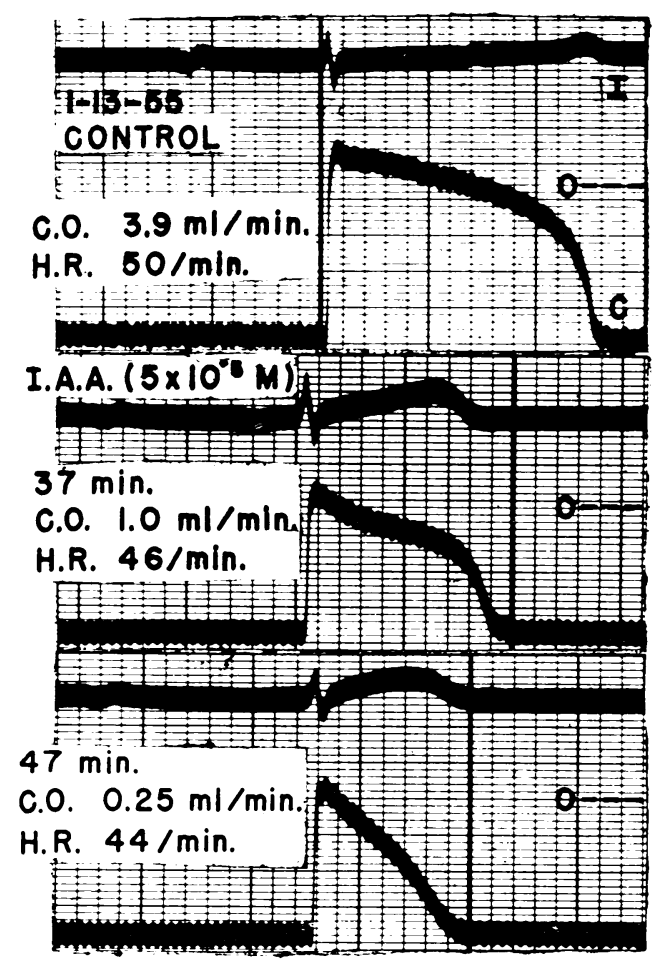

Fig. 1

Fici. 1. The Effect of $5 \times 10^{-5} \mathrm{M}$ Iodoacetate (IAA), Administered as a Perfosion, ox the Electrical axd Mechanical Activities of the Isolated Frog Heart

See text for discussion. Simultaneous records are of the indirect electrocardiogram (I) and the single fiber membrane action potential (C). Cardiac output (C.O.) and heart rate (H.R.) were taken just prior to recording of the electrical potentials. Ordinates-millivolts; abscissae-time. Time lines, $0.04 \mathrm{sec}$. Gain, $0.9 \mathrm{~cm} .=50$ $\mathrm{mv}$. for intracellular potential; for indirect electrocardiogram (I) $1.0 \mathrm{~cm}$. = $1 \mathrm{mv}$.

All measurements were made from the top of the action potential trace. Dotted line indicates zero level of potential $(\mathrm{O})$ for the membrane.

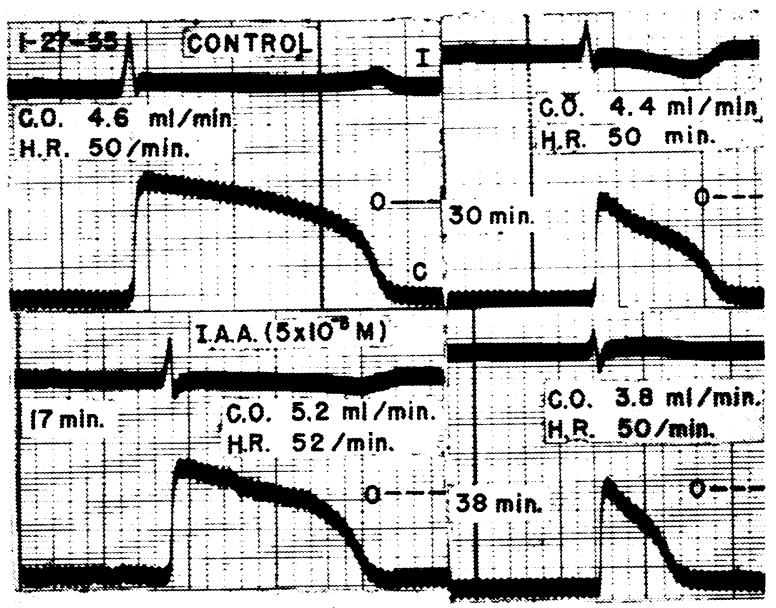

Fig, 2

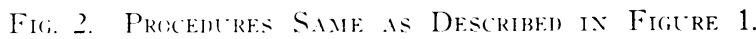

was a prolongation of the I'-R interval. During the course of the experiment. the height of the membrane action potential (MAP) slowly decreased with impaired depolarization occurring as a relatively late phenomenon. The changes in the mechanical activity were represented by a progressive decrease in cardiac output and stroke volume. Shortly after 120 minutes. the cardiac output dropped to less than $0.1 \mathrm{ml}$. and in some instances to zero and the magnitude of the membrane resting and action potentials decreased rapidly. When ventricular arrest occurred in from one to several hours atrial activity still persisted for 10 to 20 minutes. The alterations in the repolarization phase of the ventricular fiber were usually parallelled by a change in cardiac output. Figures 1 and 2 are representative of the changes described, and a summary of the data in 14 experiments is shown in Table I.

The addition of the substrates. pyruvate $(0.0055 \mathrm{M})$ and acetate $(0.0055 \mathrm{MI})$ to the IAA treated heart produced only a partial recovery and delay of ultimate deterioration of cardiac activity (Figure 3). The results were similar when ATP $\left(1.0 \times 10^{-4} \mathrm{AI}\right)$ was administered (Figure 4). Doubling the concentration of these substances did not alter the results significantly.

DISCLSSION

In the present investigation, low concentrations of ItA $\left(5 \times 10^{-5} \mathrm{M}\right)$ were used in order to study its action as a specific inhibitor of triosephosphate dehyclrogenase $(5.6)$ rather than as a general 
TABLE I

Action of iodoacetate on the frog heart *

(Averages of 14 experiments)

\begin{tabular}{|c|c|c|c|c|c|c|c|c|c|c|c|}
\hline \multirow[b]{2}{*}{$\begin{array}{c}\text { Time } \\
\text { (minutes) }\end{array}$} & \multirow{2}{*}{$\begin{array}{c}\text { Rhythmicity } \\
\text { H. R. } \\
\text { per min. }\end{array}$} & \multicolumn{2}{|c|}{ Contractility } & \multicolumn{3}{|c|}{ Indirect bipolar electrocardiogram } & \multicolumn{5}{|c|}{ Action potential } \\
\hline & & $\begin{array}{c}\text { C. O. } \\
\text { ml./min. }\end{array}$ & $\begin{array}{c}\text { S. V. } \\
m l .\end{array}$ & $\begin{array}{l}\text { P-R } \\
\text { sec. }\end{array}$ & $\begin{array}{l}\text { QRS } \\
\text { sec. }\end{array}$ & $\begin{array}{l}\text { Q-T } \\
\text { sec. }\end{array}$ & $\begin{array}{c}\mathrm{MAP} \\
m v .\end{array}$ & $\begin{array}{l}\text { MAPD } \\
\text { sec. }\end{array}$ & $\begin{array}{l}\text { APd } \\
\text { sec. }\end{array}$ & $\underset{m v .}{\mathrm{MRP}}$ & $\begin{array}{c}\text { Overshoot } \\
m v .\end{array}$ \\
\hline Control & 47 & 3.0 & 0.064 & 0.279 & 0.047 & 0.588 & 117 & 0.017 & 0.604 & 95 & 22 \\
\hline $0-20$ & 48 & 3.0 & 0.062 & 0.275 & 0.045 & 0.585 & 116 & 0.017 & 0.590 & 94 & 22 \\
\hline $20-40$ & 50 & 2.0 & 0.040 & 0.270 & 0.037 & 0.359 & 113 & 0.009 & 0.352 & 96 & 17 \\
\hline $40-60$ & 50 & 1.1 & 0.022 & 0.293 & 0.037 & 0.308 & 105 & 0.011 & 0.308 & 93 & 12 \\
\hline $80-100$ & 54 & 0.9 & 0.011 & 0.411 & 0.040 & 0.339 & 101 & 0.029 & 0.329 & 81 & 20 \\
\hline $100-120$ & 52 & 0.2 & 0.004 & 0.357 & 0.041 & 0.243 & 103 & 0.028 & 0.250 & 91 & 12 \\
\hline
\end{tabular}

* H. R. - Heart rate.

C. O. - Cardiac output.

S. V. - Stroke volume.

MAP - Membrane action potential.

MAPD-Duration of depolarization of membrane action potential.

APd -Duration of action potential.

MRP - Membrane resting potential.

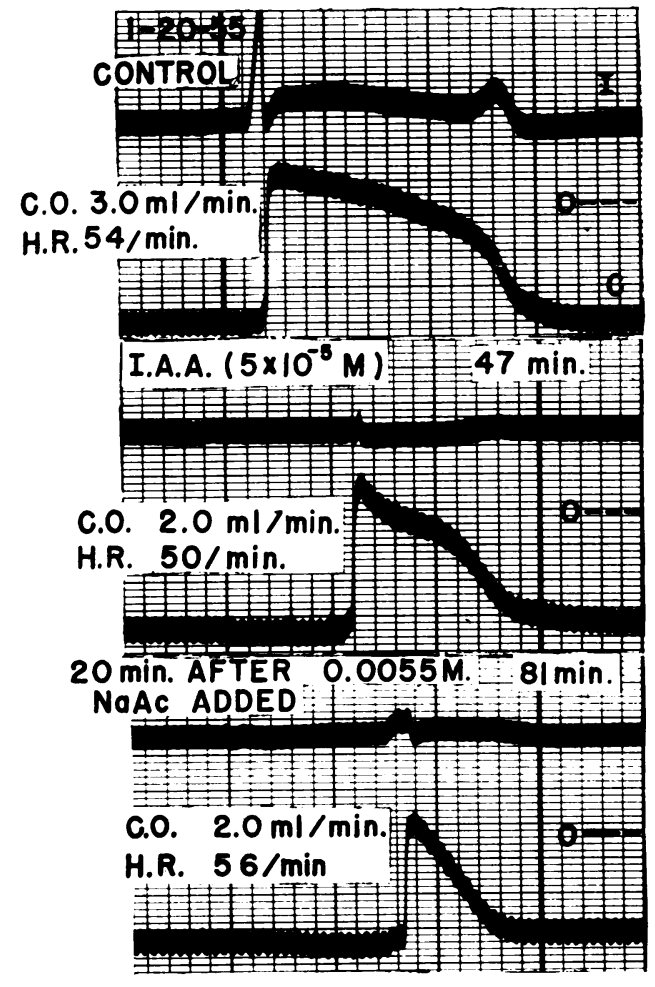

Fig. 3

Fig. 3. The Effect of $0.0055 \mathrm{M}$ Sonium Acetate (Na Ac) Added to the iAA Perfesen Frog Heart

See text for discussion. Indirect electrocardiogram (I, above); membrane action potential (C, below). Cardiac output (C.O.) and heart rate (H.R.) were taken immediately preceding the electrical recordings. Time lines, gains and zero of potential as in Figure 1. sulfhydryl inhibitor which is the case with concentrations in excess of $10^{-3} \mathrm{M}(6,7)$. The observations were extended over a relatively long period ( 1 to 3 hours) in contrast to some of the earlier experiments (2). The most striking finding in this series was the similar degree of susceptibility of the electrical and mechanical properties to the action of IAA (Table I). The alterations in mechanical activity were usually parallelled by changes in the electrical potential, the most prominent of which was enhanced repolarization of the cell (shortened APd). This is at variance with the observations of Gardner, Wilson, and Farah (4) stated above. The different cardiac tissue and dosages employed by Gardner, Wilson, and Farah $(4,9)$ do not, in our opinion, account for the differences in the results obtained. It is believed that the diverse results are ascribable to the different techniques employed for recording the action potential. Gardner, Wilson, and Farah (4, 9) measured only its height. Detailed analysis was difficult because of the variations observed from auricle to auricle. Reduction in the height of the action potential was reported as gradual, but considerably less than the percentage reduction in contractility. By means of the intracellular microelectrode utilized in our study, it was possible to measure all the parameters of the intracellular action potential and the results disclosed a close correlation and parallellism between electrical and mechanical events. 


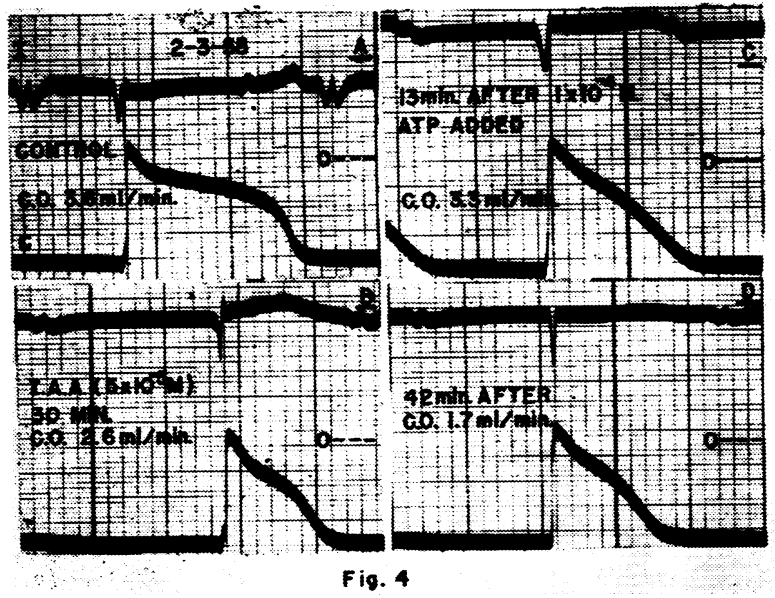

Fig. 4. The Effect of $1.0 \times 10^{-4} \mathrm{M}$ Adenosine Triphosphate (ATP) Added to the IAA Perfused Frog HEART

Discussion in text. Indirect electrocardiogram (I, above); membrane action potential ( $\mathrm{C}$, below). Technique and symbols are as indicated in Figure 1.

Although it is probable that differential energy gradients exist for the various cardiac functions, it is difficult to explain the changes observed on the basis of quantitative differences in energy requirements. The fact that the repolarization phase of the action potential was influenced at approximately the same time as the cardiac output and stroke volume and at times preceded the latter argues strongly against Gardner, Wilson, and Farah's explanation. It is possible that under the conditions of our experiments, IAA does not act solely on energy pathways and the early modifications of the electrical potential may be due to a direct effect on the membrane per se. It is significant that Reilly, Riker, Whitehouse, and Kuriaki (12), using methyl fluoroacetate (MFA) on the papillary muscle of the cat, also observed that those events associated with the electrical restorative processes of the fiber are profoundly altered, as are the effects on the contractile mechanism. The continued interference with repolarization by MFA led to a decay in the contractile mechanism and eventually to conductive failure. Of added interest was the observation that stronger antioxidative agents like cyanide, disrupted both the mechanical and electrical events simultaneously and quite rapidly. The experiments of Reilly, Riker, Whitehouse, and Kuriaki (12) and our own, using MFA and IAA respectively, indicate that alterations of repolarization are usually as- sociated with a change in contractility. To demonstrate this it is essential to measure all components of the electrical and mechanical phases of cardiac activity.

Our results with the substrates, pyruvate and acetate, are contrary to those of Chang (2) who reported that pyruvate and other metabolic intermediates completely reversed the effects on contractility and spontaneous rate caused by iodoacetate. On the other hand, Gardner, Wilson, and Farah (4) observed that recovery by these substrates could be demonstrated only with short exposures to iodoacetate and even then were not as striking as shown by Chang. With longer exposures, as was employed in our experiment, the metabolic intermediates were only briefly effective. The inability to counteract the IAA by these substrates suggests that an additional site of action of the inhibitor exists. The latter opinion has also been expressed by other investigators $(9,13)$. It has been claimed that in relatively large doses, IAA acts as a general sulfhydryl inhibitor, whereas in low concentrations in the isolated enzyme system it has been shown to be a specific inhibitor of triosephosphate dehydrogenase. It is pertinent that Reisberg (14), studying the effect of various sulfhydryl inhibitors on the action of cholinacetylase reported no impairment with IAA in concentrations of $5 \times 10^{-5} \mathrm{M}$ or less.

The exact mechanism responsible for the enhanced repolarization phase of the trans-membrane potential observed with IAA is not known. If we accept the postulate of Hodgkin (15) that sodium permeability is principally associated with the phase of depolarization and potassium permeability with the phase of repolarization of the action potential, it is suggested that the action of IAA is associated with an enhanced permeability to potassium during cellular activity. The recent studies of Love, Cronvich, and Burch (16) on the mechanism controlling cation concentrations in the human erythrocyte revealed that iodoacetate was associated with an increased outflow of cellular potassium and a net gain of sodium. The observations lend support to our interpretation.

\section{SUMMARY AND CONCLUSIONS}

Microelectrodes were inserted into the interior of single ventricular fibers of isolated perfused 
frog hearts, and the effects of $5 \times 10^{-5} \mathrm{M}$ iodoacetate on the intracellular potential, the indirect electrocardiogram and cardiac output were recorded.

Prominent changes in both the electrical and mechanical properties were observed. The most consistent and earliest of these was a shortening of the duration of the action potential (APd) and this was progressive. Coincident with this a shortened $\mathrm{S}-\mathrm{T}$ interval and abnormal $\mathrm{T}$ wave were observed in the indirect electrocardiogram. Of lesser frequency and occurring late was a prolongation of the P-R interval. The height of the MAP slowly decreased with impaired depolarization occurring as a relatively late phenomenon. The changes in mechanical activity were represented by a progressive decrease in cardiac output and stroke volume. Auricular activity persisted for 10 to 20 minutes after ventricular arrest. The early alterations in mechanical activity of the ventricle were usually parallelled by changes in the repolarization phase of the action potential (shortened APd). The observation makes it difficult to ascribe quantitative differences in energy requirements to these two cardiac functions.

The addition of substrates, pyruvate $(0.0055 \mathrm{M})$ and acetate $(0.0055 \mathrm{M})$, to the IAA perfused heart produced only a partial recovery and delay of ultimate deterioration of cardiac activity. A similar result was obtained when adenosine tri-phosphate $\left(1.0 \times 10^{-4} \mathrm{M}\right)$ was added. Doubling the concentration of these substances did not significantly alter the results. The inability of these metabolic intermediates to restore the cardiac activity suggests that IAA has actions other than specific inhibition of triosephosphate dehydrogenase.

It is postulated that the enhanced repolarization is associated with an increased migration of $\mathrm{K}+$ out of the cell during its electrical activity.

\section{REFERENCES}

1. Clark, A. J., Eggleton, M. G., Eggleton, P., Gaddie, R., and Stewart, C. P., The Metabolism of the Frog's Heart. London, Oliver and Boyd, 1938.
2. Chang, I., The action of iodoacetate and fluoride on the isolated rabbit's auricle. Quart. J. Exper. Physiol., 1938, 28, 137.

3. Webb, J. L., The actions of metabolic substrates and inhibitors on the rabbit auricle. Brit. J. Pharmacol., 1950, 5, 87.

4. Gardner, E. A., Wilson, M., and Farah, A., The action of iodoacetate on the isolated rabbit auricle. J. Pharmacol. \& Exper. Therap., 1954, 110, 166.

5. Adler, E., von Euler, H., Günther, G., and Plass, M., Flavinenzyme im Tierkörper. Skandinav. Arch $f$. Physiol., 1939, 82, 61.

6. Green, D. E., Needham, D. M., and Dewan, J. G., Dismutations and oxidoreductions. Biochem. J., 1937, 31, 2327.

7. Dixon, M., Action of iodoacetate on dehydrogenases and alcoholic fermentation. Nature, 1937, 140, 806.

8. Miller, O. N., and Olson, R. E., Metabolism of cardiac muscle. VII. The effect of inhibitors on the metabolism of pyruvate and DL-lactate. Arch. Biochem. \& Biophys., 1954, 50, 257.

9. Gardner, E. A., and Farah, A., The action of some enzyme inhibitors on the isolated rabbit auricle. J. Pharmacol. \& Exper. Therap., 1954, 111, 255.

10. Bülbring, E., Die Wirkung einiger neuerer Herzmittel am durchrströmten Froschherz. Arch. f. exper. Path. u. Pharmakol., 1930, 152, 257.

11. Kleinfeld, M., Stein, E., and Meyers, S., Effects of barium chloride on resting and action potentials of ventricular fibers of the frog. Circ. Research, 1954, 2, 488.

12. Reilly, J., Riker, W. F., Jr., Whitehouse, W. C., and Kuriaki, K., The actions of methyl fluoroacetate on the papillary muscle of the cat with comparative experiments on the actions of methyl chloroacetate. J. Pharmacol. \& Exper. Therap., 1953, 108, 393.

13. Shorr, E., The relation of hormones to carbohydrate metabolism in iitro. Cold Spring Harbor Symposia on Quantitative Biology, 1939, 7, 323.

14. Reisberg, R. B., Sulfhydryl groups of choline acety1ase. Biochim. et Biophys. Acta, 1954, 14, 442.

15. Hodgkin, A. L., The ionic basis of electrical activity in nerve and muscle. Biol. Rev., 1951, 26, 339.

16. Love, W. D., Cronvich, J. A., and Burch, G. E., Mechanisms controlling cation concentrations in the human cell: Evidence from the effect of iodoacetate on $\mathrm{Na}$ and $\mathrm{K}$ exchange rates of the erythrocyte. J. Clin. Invest., 1955, 34, 61. 